\title{
Genetic Parameters Estimates Associated to Conversion of Nicotine to Nornicotine in Burley Tobacco
}

\author{
Bruna Line Carvalho', Magno Antonio Patto Ramalho' ${ }^{1}$ Carlos Eduardo Pulcinelli², \\ Adriano Teodoro Bruzi ${ }^{*}$ \\ ${ }^{1}$ Department of Biology, Genetics and Breeding of Plants Program, Universidade Federal de Lavras, Lavras, Brazil \\ ${ }^{2}$ Souza Cruz SA, Rio Negro, Brazil \\ ${ }^{3}$ Department of Agriculture, Universidade Federal de Lavras, Lavras, Brazil \\ Email: ${ }^{*}$ adrianobruzi@dag.ufla.br
}

Received 8 August 2014; revised 22 September 2014; accepted 25 October 2014

Copyright (C) 2014 by authors and Scientific Research Publishing Inc.

This work is licensed under the Creative Commons Attribution International License (CC BY).

http://creativecommons.org/licenses/by/4.0/

(c) (i) Open Access

\begin{abstract}
Nicotine represents the predominant alkaloid in cultivated tobacco. In burley varieties, during senescence and curing of leaves, nicotine can be converted to nornicotine, which is highly undesirable because of its relationship with the tobacco specific nitrosamines formation. Thus, an alternative for producing varieties with low or null nornicotine content would be to select plants or progenies for traits related to nicotine conversion. Therefore, understanding genetic control and inheritance underlying this process is important to chooseappropriate strategies in breeding programs. Two contrasting inbred lines for nicotine conversion to nornicotine, TN 90 and BY 37, have been crossed to obtain the segregating generations $\left(F_{2}\right.$ and $\left.B C s\right)$. Genetic parameters of mean and variance, as well as the average degree of dominance and heritability were estimated. It has been found that nicotine conversion has predominantly additive effects, and in addition, narrow sense heritabilities at the individual level were higher than $65 \%$. Both are desirable conditions for conducting a selection program of burley tobacco aiming at development of inbred lines associating yield and other traits with low or null nicotine conversion.
\end{abstract}

\section{Keywords}

Quantitative Genetics, Plant Breeding, Nicotianatabacum L., Genetic Control, Inheritance

\footnotetext{
${ }^{*}$ Corresponding author.
} 


\section{Introduction}

One of the major alkaloids produced by tobacco (Nicotianatabacum L.) is nicotine and represents $90 \%-97 \%$ of the total alkaloid content [1]-[3]. During curing and processing of tobacco products, part of the nicotine may be converted to nornicotine by the enzyme nicotine $N$-demethylase [4]-[6]. Nornicotine is considered one of the most detrimental alkaloid once itis a precursor of tobacco-specific nitrosamines (TSNAs) [7] [8], specifically Nnitrosonornicotine (NNN), which is classified as a risk substance into tobacco products [8] [9] (Figure 1). From this prospective, nornicotine is undesirable because it converts to TSNAs through nitrosation [10]. Consequences caused by nornicotine effects can be found in the literature [11]-[13].

For that reason and considering that tobacco is consumed primarily in the form of cigarettes, one of the goals of a tobacco plant breeder is to develop very productive varieties keeping nornicotine levels to a minimum [14] [15]. In fresh tobacco leaves, nornicotine represents $<5 \%$ of the total alkaloid content [1], but its level may increase considerably by a natural mechanism called conversion, which transforms as much as $99 \%$ of nicotine to nornicotine [1] [16].

Conversion occurs mainly during senescence and curing [17]. Tobacco varieties that convert a high portion of their nicotine content into nornicotine are referred to as "converters", in contrast to those that retain nicotine as their predominant alkaloid-“non-converters”. Although conversion is a common process in all tobacco groups, the frequency of conversion in burley varieties is higher than in flue-cured tobacco [3] [18].

Several studies aiming to determine the genetic mechanism underlying this process have been conducted. The first studies have shown that a single dominant gene has controlled the difference between high and low nornicotine varieties [19]-[21]. This gene has been isolated and it was seen to encode a cytochrome P450 monooxygenase, which is expressed during senescence and in response to ethylene treatment [3] [22]. Although this gene plays an important role in the nornicotine biosynthetic pathway, there are many other genes and regulators involved in nornicotine formation.

Many technologies are being studied in an attempt to reduce nornicotine produced in tobacco leaf. RNA interference (RNAi) has been used to induce post-transcriptional gene silencing on genes controlling nornicotine synthesis [3] [22] [23]. This technique allows degradation of target mRNA of specific sequences [24]. Another option would be to randomly insert chemical mutations into the tobacco genome and search for plants in which the nicotine $N$-demethylase gene is permanently impaired [23] [25]. However, the expression of other genes in plants can be altered by these two methods as a result of unknown effects of these techniques in other genes controlling important traits, for instance growth, or resistance to insects and diseases.

An alternative strategy would be to select plants and progenies in a conventional manner with the same effect, without using genetic engineering. Therefore, understanding the genetic control and inheritance underlying the nicotine conversion in superior varieties is important for selecting efficient methods and strategies for increasing yield while minimizing nornicotine content. This was the aim of the present study. Thus, we show the predominant effect in genetic control of nicotine conversion and alternatives that may lead to a higher gain in decreasing nornicotine in tobacco leaves.

\section{Materials and Methods}

\subsection{Plant Material and Field Evaluation}

All plant materials used in this study were provided by Souza Cruz SA. Two contrasting burley inbred lines, TN 90 ("non-converter") and BY 37 (“converter”), were crossed to obtain the $\mathrm{F}_{1}$ generation. $\mathrm{F}_{1}$ plants were crossed with both parents and self-pollinated to generate backcrosses (BCs) and the $\mathrm{F}_{2}$ population, respectively (Figure 2). The $F_{1}$ generation was not evaluated.

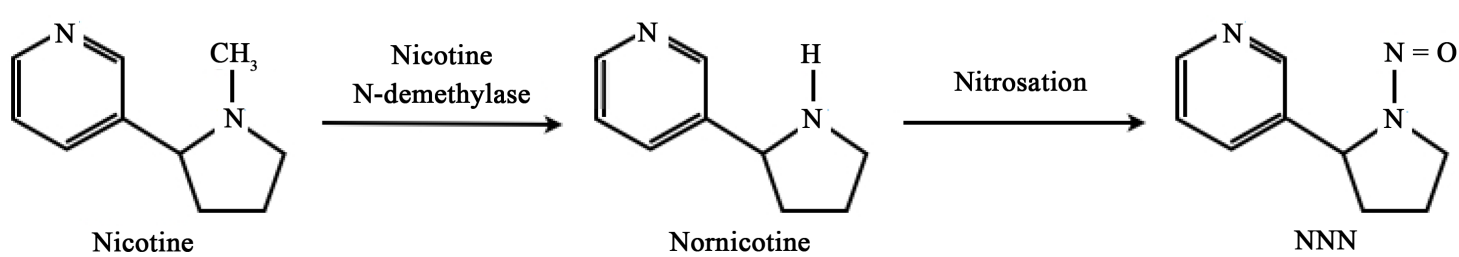

Figure 1. Simplified pathway of nicotine conversion process, and structures of nicotine, nornicotine and NNN. 


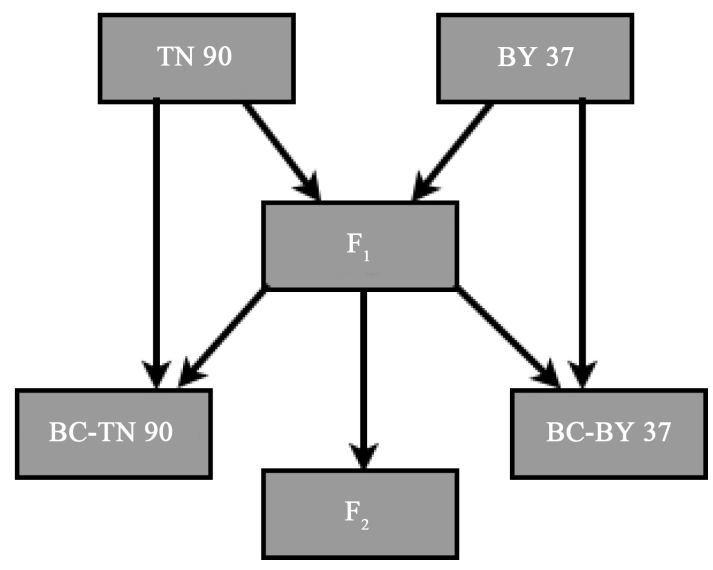

Figure 2. Dynamics of how generations were obtained.

Field evaluation was carried out in Rio Negro, PR, Brazil in the 2013/2014 crop season. A randomized complete block design with two replications was used. Different numbers of plants were evaluated per generation: 40 from TN 90, 40 from BY 37, 200 from the $F_{2}$ generation, 200 from BC-TN 90, and 200 from BC-BY 37. They were randomized into the two replications in experimental units consisting of a single 10-plant row. Data was collected at the individual level.

\subsection{Chemical Analysis}

Quantitative determinations of nicotine and nornicotine in cured leaf samples were carried out for each plant in the plot. The analysis was done at the Product Center Laboratory of Souza Cruzlocated in Porto Alegre, RS, Brazil. The samples were extracted and the quantification of the nicotine and nornicotine was performed by gas chromatography. The results were reported as $\mu \mathrm{g} / \mathrm{g}$ of leaf tissue for nicotine and nornicotine content, and as percentages for conversion. The percentage of nicotine conversion was calculated as:

$[$ nornicotine content/(nornicotine content+nicotine content $)] \times 100$.

\subsection{Statistical Analysis}

Data was subjected to analysis of variance for randomized complete block design using R software [26]. The accuracy of the evaluation for all traits was calculated by: $\sqrt{1-1 / F}$ [27], in which $F$ is the statistic of $F$-Snedecor for treatments.

Genetic components of mean were estimated using generation means (parents, $F_{2}$ and BCs), through the approach proposed by Rowe and Alexander [28]. The proportion of the total variation among the generation means explained by the genetic model was obtained through the coefficient of determination $\left(R^{2}\right)$ and used to test the additive-dominant model with and without epistatic effects.

Genetic components of variance were estimated by iterative weighted least square [29]. The variance was partitioned in environmental $\left(V_{E}\right)$, additive $\left(V_{A}\right)$ and dominant $\left(V_{D}\right)$. Also, the $R^{2}$ coefficient was calculated to measure the variation explained by the model. The narrow sense heritability $\left(h^{2}\right)$ at the individual level was estimated using the following expression: $h^{2}=\frac{V_{A}}{V_{A}+V_{D}+V_{E}}$ [30].

Pearson phenotypic correlation was estimated between the total nicotine content before leaf curing, and the nornicotine after curing using plants of the $F_{2}$ generation by: $r_{P}=\frac{C O V_{x y}}{\sqrt{V_{x} V_{y}}}$ [31], in which $C O V_{x y}$ is the phenoltypic covariance between the traits and $V_{x}$ and $V_{y}$ are the phenotypic variances of each trait independently. The $t$ test was applied to $r_{P}$ to check whether the estimate is not equal to zero.

\section{Results}

The means of each trait for the generations are shown in Table 1 and frequency distribution in Figure 3 . The 
Table 1. Means and intra-generational variances for nicotine and nornicotine content, and nicotine conversion, obtained for the parents and the segregating populations of tobacco.

\begin{tabular}{ccccccc}
\hline & \multicolumn{2}{c}{ Nicotine $(\mu \mathrm{g} / \mathrm{g})$} & \multicolumn{2}{c}{ Nornicotine $(\mu \mathrm{g} / \mathrm{g})$} & \multicolumn{2}{c}{ Conversion $(\%)$} \\
\hline Generation & Mean & Variance & Mean & Variance & Mean & Variance \\
TN 90 & 12,599 & $3,570,178$ & 397 & 45,556 & 3.14 & 3.88 \\
BY 37 & 202 & 168,382 & 8674 & $1,304,658$ & 98.06 & 15.08 \\
Parents average & 6401 & & 4535 & & 50.60 & 1108.81 \\
$F_{2}$ & 6295 & $20,506,162$ & 5272 & $13,325,445$ & 48.36 & 15.15 \\
BC-TN 90 & 10,411 & $11,542,958$ & 1642 & $5,857,273$ & 523.55 \\
BC-BY 37 & 1697 & $5,433,430$ & 8753 & $5,630,094$ & 84.53 & 421.90 \\
\hline
\end{tabular}

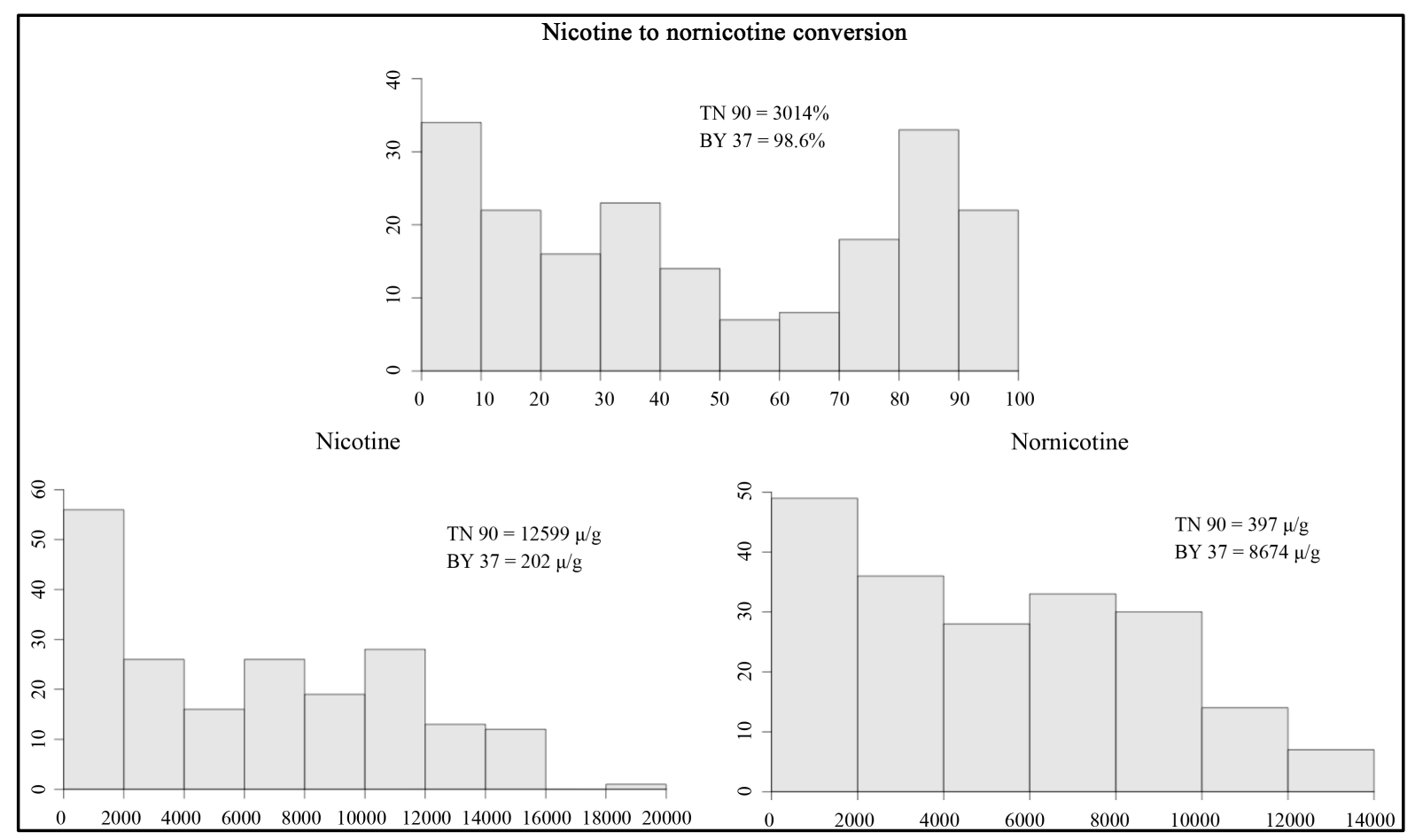

Figure 3. Distribution of frequency in number of individuals from $F_{2}$ generation, Y-axis, for nicotine conversion (\%), nicotineand nornicotinecontent $(\mu \mathrm{g} / \mathrm{g})$, X-axis, obtained from crossing of tobacco inbred lines, TN $90 \times$ BY 37 .

parents proved to be contrasting for all traits, which is vital for this kind of study. The means of the $F_{2}$ with respect to all the characters studied were approximately equal to the means of the parents. The mean values of BCs tend to the recurrent parent, as expected. Figure 3 shows a high segregation for the $F_{2}$ generation, indicating, initially, that several genes are responsible for phenotypic expression of the traits. The variances of the $F_{2}$ generation were higher than the variances in the other generations, and BCs showed intermediate variances, congruent to what was expected.

Estimates of genetic parameters are shown in Table 2 and Table 3. The additive-dominant model explained most of the variation $\left(R^{2}=94 \%\right)$. Additive gene effects $(a)$ were relatively high compared to dominance deviation $(d)$, and the values were significantly different from zero (Table 2). However, the generation means depends not only on additive effects, but also on dominance effects in determining the trait means, although to a low degree. The estimates of the average degree of dominance (add) confirm this observation.

The estimates of environmental $\left(V_{E}\right)$, additive $\left(V_{A}\right)$ and dominance $\left(V_{D}\right)$ variance, as well as the narrow sense of heritability $\left(h^{2}\right)$ are shown in Table 3 . The adequacy of the additive-dominance model was higher than $94 \%$, indicating a good fit. The standard deviations had magnitudes lower than the estimates, indicating that both $V_{A}$ 
Table 2. Genetic parameters estimated by an additive-dominant model with respective standard deviation; average degree of dominance ( $a d d$ ); and $R^{2}$ coefficient for three traits in tobacco: nicotine, nornicotine and conversion.

\begin{tabular}{|c|c|c|c|c|c|c|}
\hline \multirow[b]{2}{*}{ Parameters } & \multicolumn{2}{|c|}{ Nicotine $(\mu \mathrm{g} / \mathrm{g})$} & \multicolumn{2}{|c|}{ Nornicotine $(\mu \mathrm{g} / \mathrm{g})$} & \multicolumn{2}{|c|}{ Conversion (\%) } \\
\hline & Estimate & $\mathrm{SD}^{1}$ & Estimate & SD & Estimate & SD \\
\hline Mean & 6893.20 & \pm 138.76 & 4878.57 & \pm 86.78 & 50.91 & \pm 0.34 \\
\hline$a$ & -6739.84 & \pm 135.65 & 4506.62 & \pm 85.99 & 47.98 & \pm 0.34 \\
\hline$d$ & -2229.98 & \pm 349.34 & 746.38 & \pm 282.49 & -0.45 & \pm 2.12 \\
\hline add & -0.32 & & 0.15 & & -0.01 & \\
\hline$R^{2}$ & 98.11 & & 95.60 & & 93.25 & \\
\hline
\end{tabular}

${ }^{1}$ Standard deviation.

Table 3. Estimates of environmental $\left(V_{E}\right)$, additive $\left(V_{A}\right)$ and dominant $\left(V_{D}\right)$ variance with respective standard deviation, narrow sense heritability $\left(h^{2}\right)$ and the $R^{2}$ coefficient for three traits in tobacco: nicotine, nornicotine and conversion.

\begin{tabular}{ccccccc}
\hline & \multicolumn{2}{c}{ Nicotine $(\mu \mathrm{g} / \mathrm{g})$} & \multicolumn{2}{c}{ Nornicotine $(\mu \mathrm{g} / \mathrm{g})$} & \multicolumn{2}{c}{ Conversion $(\%)$} \\
\hline Parameters & Estimate & \multicolumn{1}{c}{$\mathrm{SD}^{1}$} & Estimate & SD & Estimate & SD \\
$V_{E}$ & 175,932 & $\pm 38,587$ & 47,090 & $\pm 10,445$ & 4.57 & \pm 0.86 \\
$V_{A}$ & $13,734,820$ & $\pm 2,585,295$ & $8,664,871$ & $\pm 1,685,781$ & 726.95 & \pm 140.14 \\
$V_{D}$ & $6,595,410$ & $\pm 802,806$ & $4,613,485$ & $\pm 539,551$ & 377.28 & \pm 44.48 \\
$h^{2}$ & 0.67 & & 0.65 & & 0.66 & \\
$R^{2}(\%)$ & 94.25 & & 94.10 & & 96.72 &
\end{tabular}

${ }^{1}$ Standard deviation.

and $V_{D}$ were different from zero. The estimated $V_{A}$ and $V_{D}$ components were consistent with $a$ and $d$ described before. Heritability $\left(h^{2}\right)$ represents another parameter that provides information about the genetic control of the trait and allows us to infer whether the trait can be easily selected. In the present study, narrow sense heritability at plant level was relatively high for all characters (>65\%). In this case, $h^{2}$ only represents additive genetic variance, which is associated with the breeding value an individual can transmit to its progeny.

\section{Discussion}

Quantification of nicotine and nornicotine content, as well as the conversion rate, were performed with high precision, as can be confirmed by the high experimental accuracies ( $>92 \%$, data not shown) and the low environmental variances related to the genetic variance components (Table 3). Thus, breeders can efficiently evaluate the designated traits during the selection process.

Understanding the genetic determination of traits helps the breeder in formulating breeding techniques for combining desirable characters that are dispersed in two or more genotypes into one. Identification of the sources contributing to genetic variation and the type of gene actions involved will assist in the selection of the most appropriate breeding strategy.

If we consider one gene with two alleles, $B$ and $b$, we have one of three possible genotypes in the $F_{2}$ generation or any other segregating generation: $B B, B b$ and $b b$. The phenotypic expression of each genotype is determined as the departure from the mid-point $(m)$ between two homozygous parents $(B B$ and $b b$ ). Thus, parameter $a_{B}$ measures the departure of each homozygote from $m$, and $d_{B}$ measures the departure of the heterozygote from $m$ (Figure 4). The phenotypic expression of $B B$ and $b b$ would be $m+a_{B}$ and $m-a_{B}$, respectively, and that of $B b$ would be $m+d_{B}$. When more than one locus is involved, the expected phenotypic expression of each genotype is determined as the sum of the effects at the individual loci [29]; therefore this model can be extended to any number of loci. Therefore, $a$ represents the additive effect if dominance is absent $(d=0)$ or allelic frequency is $0.5(B=b)$, that is when we cross two inbred lines [30]. The magnitude of $d$ will change depending upon the degree and direction of dominance (add), i.e., the $d / a$ ratio.

The model can also be extended to include non-allelic (epistatic) interaction components [29]. The $R^{2}$ coeffi- 


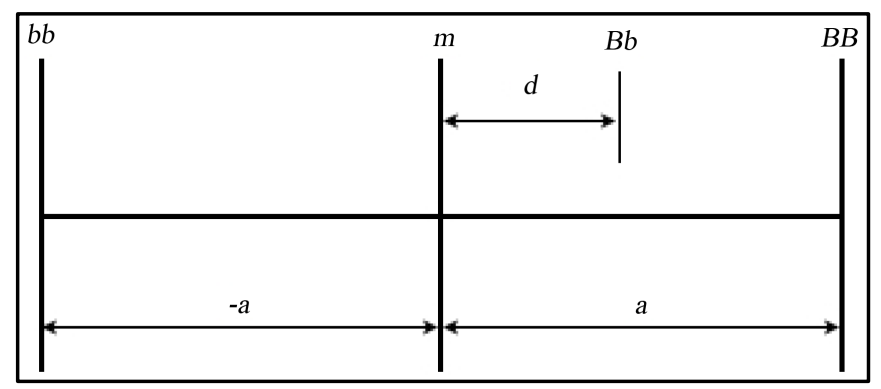

Figure 4. Additive $(a)$ and dominant $(d)$ genetic parameter for a given locus- $B$. Deviations are relative scales to the mid-point $(m)$ between two parents.

cient can be used to choose the most adequate model. Since the estimates of this coefficient were high for all cases (>94\%), the epistatic effects should be minimum or null. Thus, adequacy of the simple model, i.e., main effects alone, was satisfactory.

The estimates obtained showed predominance of additive effects, evidenced by add. Nevertheless, $d$ is not negligible. In early literature, the information found is that trait is controlled by one gene with dominance for the allele controlling nicotine conversion [19]-[21]. This is in agreement with the idea of dominance in the traits genetic control; however, more genes of minor effect must be involved in the biosynthetic pathway because of the quantitative distribution observed in segregating generations (Figure 3). These genes may be responsible for encoding precursors of nicotine and nornicotine or for regulating transcripts that somehow affects the route.

$V_{A}$ and $V_{D}$ estimates were consistent with $a$ and $d$, as already stated. According to Bernardo [30], $V_{A}$ does not have a clear meaning, because the term additive does not imply that the alleles have only additive effects. This concept can be better elucidated by its estimator: $V_{A}=2 p q[a+d(q-p)]^{2}$, in which $p$ and $q$ are the frequencies of each allele. The expression indicates that any segregating locus, with or without dominance, can contribute to $V_{A}$. Therefore, the presence of $V_{A}$ does not mean that the allele effects are purely addictive. Therefore, even though low, a degree of dominance was found in the expression of the traits. However, the variance components generally have high errors associated with the estimates, probably because the data is recorded at the individual level.

In the literature, estimates of mean and variance components were not found for the traits evaluated in this study. There are reports referring to the number of genes controlling the phenotypic expression. Moreover, in a study performed involving crosses between $N$. tabacum and related amphidiploids two genes controlling nicotine conversion were found [32]. In contrast, other studies indicate that one gene is responsible for expression of the trait as already mentioned. Yet for other traits in tobacco, information regarding to genetic components of mean and variance is scarce. Some researchers have performed diallel crosses and evaluated traits associated with tobacco yield [33]-[35]. For all traits evaluated the general combining ability (GCA) was higher than the specific combining ability (SCA), indicating absence of heterosis and, consequently, predominance of additive effects.

For that reason, the selection of plants with low or null nicotine conversion is likely the best strategy for achieving success in breeding programs. Additionally, the narrow sense heritability estimate at the individual level for nicotine conversion was relatively high (76\%), which indicates a favorable condition for selection in early generations when practicable. Even so, selection should be associated with a recurrent program because it is not possible to reach the desired nornicotine content after just one selection cycle. One more point to take into considerations is the low correlation estimate $\left(r_{P}\right)$ between the total nicotine content before leaf curing and the nornicotine content after curing $(-0.09$; p-value $=0.22)$. Hence, selecting for nicotine content does not imply in any consequences for nicotine conversion. In other words, the breeder can select "non-converters" plants with low nicotine content.

In production of foundation seeds, for example, a screening is carried out on all plants to eliminate individuals that exhibit nicotine conversion higher than 3\% [36]. In this context, Lewis et al. [37] indicated another evidence for quantitative inheritance of nicotine conversion. To quote these authors:

"Although this screening procedure leads to significant reductions in nornicotine (and NNN) in comparison to tobacco populations that have not been screened, this process can never be perfect, since high nornicotine 
producing converter plants can spontaneously arise with each generation.”

Therefore, genetic control of this trait is not as simple as has been stated by many authors. These unexpected converter plants could be arising from changes in the epigenetic state [38]. In this case, conducting the selection program according to the environmental conditions in which the tobacco plant will be grown in the future is the best option for perpetuating epigenetic effects in the direction desired by breeders.

Since evaluation of nicotine and nornicotine is expensive and laborious, the use of molecular markers linked to one of the major genes controlling the trait could be an alternative for screening the progenies or plants in early generation before being subjected to field evaluation. Markers can be selected in a study like this through the use of a segregating population, but the sequences for primers can also already be found in scientific articles published on the issue [22]. However, it is important to emphasize that there are many other genes of low effect controlling the trait; therefore, selection of progenies and plants in experimental designs is important for making fine adjustments in the inbred lines to be released for commercial purposes.

\section{Conclusion}

Nicotine conversion had predominantly additive effects. Narrow sense heritabilities at the individual level were higher than $65 \%$. Both of these desirable conditions for conducting a selection program for burley tobacco aiming at the development of inbred lines associating yield and other traits with low or null nicotine conversion.

\section{Acknowledgements}

This is an academic study supported by Souza Cruz SA. We also thank the Coordenação de AperfeiçoamentoProfissional do Ensino Superior (CAPES) for the Ph.D. scholarship and the Conselho Nacional de Pesquisa e Desenvolvimento (CNPq) for the grant.

\section{References}

[1] Sisson, V.A. and Severson, R.F. (1990) Alkaloid Composition of the Nicotiana Species. Beitr. Tabakforsch, 14, 327399.

[2] Saitoh, F., Noma, M. and Kawashima, N. (1985) The Alkaloid Contents of 60 Nicotianaspecies. Phytochemistry, 24, 477-480. http://dx.doi.org/10.1016/S0031-9422(00)80751-7

[3] Siminszky, B., Gavilano, L., Bowen, S.W. and Dewey, R.E. (2005) Conversion of Nicotine to Nornicotine in Nicotianatabacum Is Mediated by CYP82E4, a Cytochrome P450 Monooxygenase. Proceedings of the National Academy of Sciences of the United States of America, 102, 14919-14924. http://dx.doi.org/10.1073/pnas.0506581102

[4] Hao, D.Y. and Yeoman, M.M. (1996) Mechanism of Nicotine N-Demethylation in Tobacco Cell Suspension Cultures. Phytochemistry, 41, 477-482. http://dx.doi.org/10.1016/0031-9422(95)00532-3

[5] Hao, D.Y. and Yeoman, M.M. (1996) Nicotine N-Demethylase in Cell-Free Preparations from Tobacco Cell Cultures. Phytochemistry, 42, 325-329. http://dx.doi.org/10.1016/0031-9422(95)00868-3

[6] Hao, D.Y. and Yeoman, M.M. (1998) Evidence in Favour of an Oxidative N-Demethylation of Nicotine to Nornicotine in Tobacco Cell Cultures. Journal of Plant Physiology, 152, 420-426. http://dx.doi.org/10.1016/S0176-1617(98)80258-7

[7] Hecht, S.S. (1998) Biochemistry, Biology, and Carcinogenicity of Tobacco-Specific N-Nitrosamines. Chemical Research in Toxicology, 11, 559-603. http://dx.doi.org/10.1021/tx980005y

[8] Williams, D.L.H. (1999) The Chemistry of S-Nitrosothiols. Accounts of Chemical Research, 32, 869-876. Cancer. Cancer Surv., 8, 273-294.

[9] Hecht, S.S. and Hoffmann, D. (1989) The Relevance of Tobacco-Specific Nitrosamines to Human Cancer. Cancer Surv., 8, 273-294.

[10] Li, Q., Krauss, M.R. and Hempfling, W.P. (2006) Wounding of Root or Basal Stalk Prior to Harvest Affects PreHarvest Antioxidant Accumulation and Tobacco-Specific Nitrosamine Formation during Air Curing of Burley Tobacco (Nicotianatabacum L.). Journal of Agronomy and Crop Science, 192, 267-277. http://dx.doi.org/10.1111/j.1439-037X.2006.00217.x

[11] Dickerson, T.J. and Janda, K.D. (2002) A Previously Undescribed Chemical Link between Smoking and Metabolic Disease. Proceedings of the National Academy of Sciences of the United States of America, 99, 15084-15088. http://dx.doi.org/10.1073/pnas.222561699

[12] Katz, J., Caudle, R.M., Bhattacharyya, I., Stewart, C.M. and Cohen, D.M. (2005) Receptor for Advanced Glycation 
End Product (RAGE) Upregulation in Human Gingival Fibroblasts Incubated with Nornicotine. Journal of Periodontology, 76, 1171-1174. http://dx.doi.org/10.1902/jop.2005.76.7.1171

[13] Brogan, A.P., Dickerson, T.J., Boldt, G.E. and Janda, K.D. (2005) Altered Retinoid Homeostasis Catalyzed by a Nicotine Metabolite: Implications in Macular Degeneration and Normal Development. Proceedings of the National Academy of Sciences of the United States of America, 102, 10433-10438. http://dx.doi.org/10.1073/pnas.0504721102

[14] Stratton, K.R., Shetty, P., Wallace, R. and Bondurant, S. (2001) Clearing the Smoke: Assessing the Science Base for Tobacco Harm Reduction. National Academy Press, Washington DC.

[15] Gartner, C.E., Hall, W.D., Vos, T., Bertram, M.Y., Wallace, A.L. and Lim, S.S. (2007) Assessment of Swedish Snus for Tobacco Harm Reduction: An Epidemiological Study. Lancet, 369, 2010-2014. http://dx.doi.org/10.1016/S0140-6736(07)60677-1

[16] Wernsman, E.A. and Matzinger, D.F. (1968) Time and Site of Nicotine Conversion in Tobacco. Tobacco Science, 12, 226-228.

[17] Bush, L.P., Cui, M., Shi, H., Burton, H.R., Fannin, F.F., Lei, L. and Dye, N. (2001) Formation of Tobacco-Specific Nitrosamines in Air-Cured Tobacco. Rec. Adv. Tob. Sci., 27, 23-46.

[18] Gavilano, L.B. and Siminszky, B. (2007) Isolation and Characterization of the Cytochrome P450 Gene CYP82E5v2 That Mediates Nicotine to Nornicotine Conversion in the Green Leaves of Tobacco. Plant and Cell Physiology, 48, 1567-1574. http://dx.doi.org/10.1093/pcp/pcm128

[19] Griffith, R.B., Valleau, W.D. and Stokes, G.W. (1955) Determination and Inheritance of Nicotine to Nornicotine Conversion in Tobacco. Science, 121, 343-344. http://dx.doi.org/10.1126/science.121.3140.343

[20] Burk, L.G. and Jeffrey, R.N. (1958) A Study of the Inheritance of Alkaloid Quality in Tobacco. Tobacco Science, 2, 139-141.

[21] Wernsman, E.A. and Matzinger, D.F. (1970) Relative Stability of Alleles at the Nicotine Conversion Locus of Tobacco. Tobacco Science, 14, 34-36.

[22] Gavilano, L.B., Coleman, N.P., Burnley, L.E., Bowman, M.L., Kalengamaliro, N.E., Hayes, A., Bush, L. and Siminszky, B. (2006) Genetic Engineering of Nicotiana tabacum for Reduced Nornicotine Content. Journal of Agricultural and Food Chemistry, 54, 9071-9078. http://dx.doi.org/10.1021/jf0610458

[23] Lewis, R.S., Jack, A.M., Morris, J.W., Robert, V.J.M., Gavilano, L., Siminszky, B., Bush, L.P., Hayes, A.J. and Dewey, R.E. (2008) RNAi-Induced Suppression of Nicotine Demethylase Activity Reduces Levels of a Key Carcinogen in Cured Tobacco Leaves. Plant Biotechnology Journal, 6, 346-354. http://dx.doi.org/10.1111/j.1467-7652.2008.00324.x

[24] Waterhouse, P.M. and Helliwell, C.A. (2004) Exploring Plant Genomes by RNA-Induced Gene Silencing. Nature Reviews Genetics, 4, 29-38. http://dx.doi.org/10.1038/nrg982

[25] Julio, E., Laporte, F., Reis, S., Rothan, C. and Dorlhac de Borne, F. (2008) Reducing the Content of Nornicotine in Tobacco via Targeted Mutation Breeding. Molecular Breeding, 21, 369-381. http://dx.doi.org/10.1007/s11032-007-9138-2

[26] R Core Team (2014) R: A Language and Environment for Statistical Computing. R Foundation for Statistical Computing. http://www.R-project.org/

[27] Resende, M.D.V. (2002) Genética Biométrica e Estatística no Melhoramento de Plantas. EmbrapaInformação Tecnológica, Brasília.

[28] Rowe, K.E. and Alexander, W.L. (1980) Computations for Estimating the Genetic Parameters in Joint-Scaling Tests. Crop Science, 20, 109-110. http://dx.doi.org/10.2135/cropsci1980.0011183X002000010027x

[29] Mather, K. and Jinks, J.L. (1982) Introduction to Biometrical Genetics. Chapman and Hall Ltd., London.

[30] Bernardo, R. (2010) Breeding for Quantitative Traits in Plants. Stemma Press, Woobury.

[31] Falconer, D.S. and Mackay, T.F.C. (1996) Introduction to Quantitative Genetics. Pearson Education Limited, Malaysia.

[32] Mann, T.J., Weybrew, J.A., Matzinger, D.F. and Hall, J.F. (1964) Inheritance of the Conversion of Nicotine to Nornicotine in Varieties of Nicotiana tabacum L. and Related Amphidiploids. Crop Science, 4, 349-353. http://dx.doi.org/10.2135/cropsci1964.0011183X000400040003x

[33] Aleksoski, J. (2010) Estimation of the Heterotic Effect in F1 Generation of Various Tobacco Genotypes and Their Diallel Crosses. Biotechnology \& Biotechnological Equipment, 24, 407-411. http://dx.doi.org/10.1080/13102818.2010.10817873

[34] Wang, Y., Cheng, J., Cai, C., Lin, G., Huang, W., Zhou, Y. and Xiao, Z. (2009) The Heterosis and Genetic Analysis of Main Agronomic Traits of Burley Tobacco. Chinese Tobacco Science, 3.

[35] Carvalho, B.L., Pullcinelli, C.E., Raposo, F.V., Ramalho, M.A.P. and Bruzi, A.T. (2013) Potencial do emprego de 
sementeshíbridasem Tabaco, grupo varietal virginia. Anais do XXII Congresso de Pós-Graduação da UFLA, Lavras.

[36] Jack, A., Fannin, N. and Bush, L.P. (2007) Implications of Reducing Nornicotine Accumulation in Burley Tobacco: Appendix A-The LC Protocol. Rec. Adv. Tob. Sci., 33, 58-79.

[37] Lewis, R.S., Bowen, S.W., Keogh, M.R. and Dewey, R.E. (2010) Three Nicotine Demethylase Genes Mediate Nornicotine Biosynthesis in Nicotiana tabacum L.: Functional Characterization of the CYP82E10 Gene. Phytochemistry, 71, 1988-1998. http://dx.doi.org/10.1016/j.phytochem.2010.09.011

[38] Raboy, V. (2013) The Future of Crop Breeding fro Nutritional Quality. SABRAO Journal of Breeding and Genetics, 45 , 100-111. 
Scientific Research Publishing (SCIRP) is one of the largest Open Access journal publishers. It is currently publishing more than 200 open access, online, peer-reviewed journals covering a wide range of academic disciplines. SCIRP serves the worldwide academic communities and contributes to the progress and application of science with its publication.

Other selected journals from SCIRP are listed as below. Submit your manuscript to us via either submit@scirp.org or Online Submission Portal.
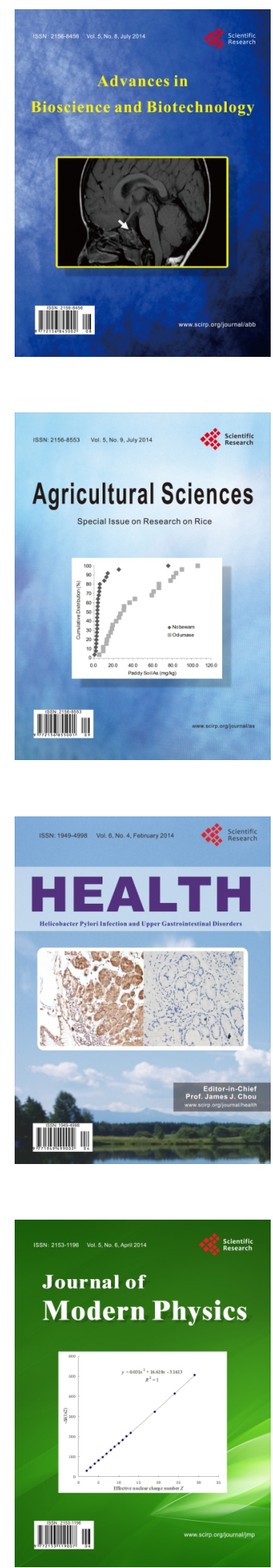
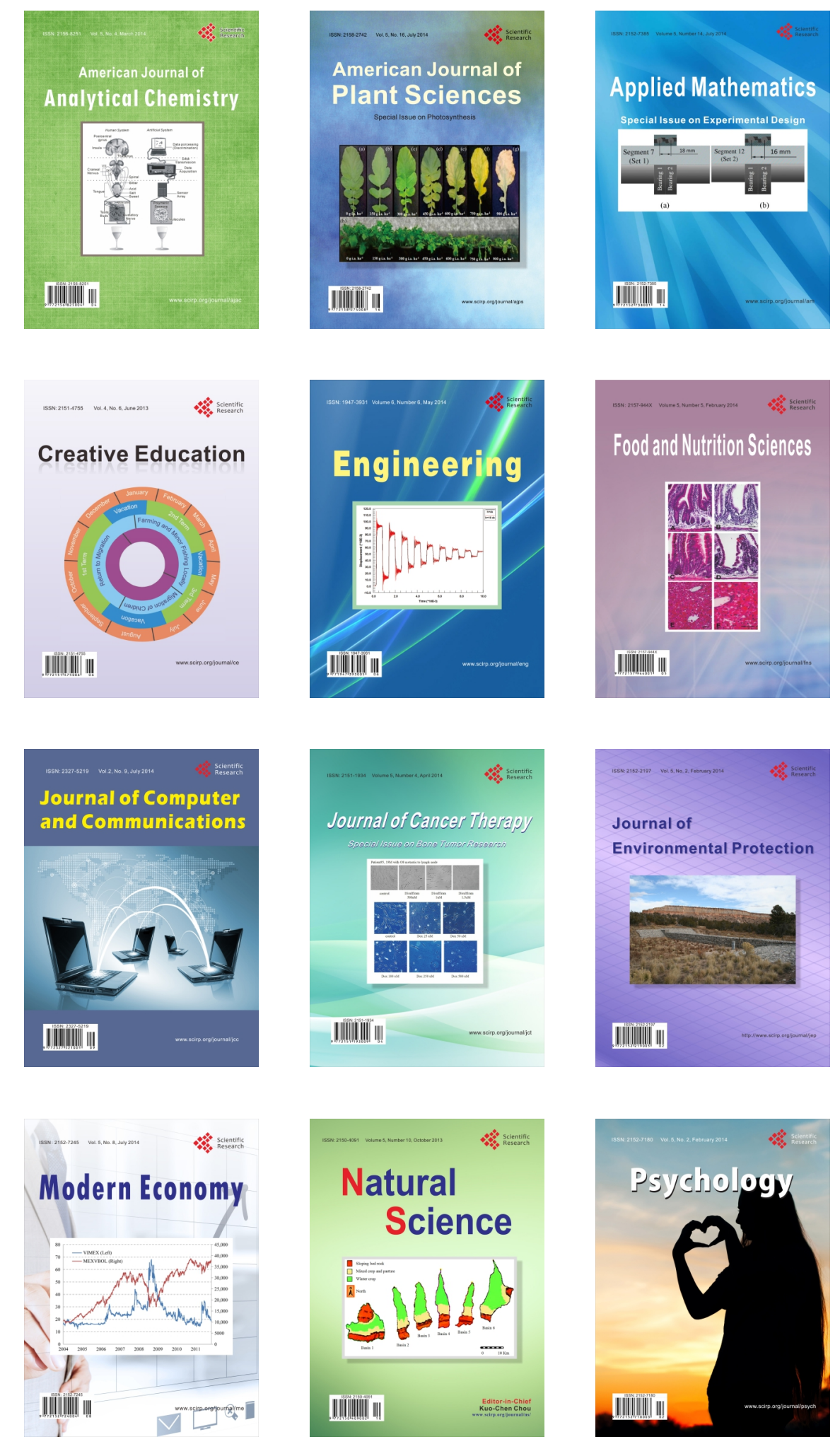